\title{
Sobre el concepto de proyección en el mundo comunicativo
}

\author{
Eva Aladro VICO \\ Universidad Complutense de Madrid \\ ealadro@ccinf.ucm.es
}

"Recuerda siempre que lo que buscas también te busca a ti" Jack Murphy

\begin{abstract}
Resumen
Este texto aborda el estudio del concepto de proyección imaginaria, desde sus orígenes psicológicos y psicoanalíticos, hasta su evolución filosófica, sociológica, antropológica y comunicacional. Se pone por primera vez de manifiesto la riqueza y fertilidad de sus aplicaciones y se ahonda en su articulación compleja, muy útil para conocer más la comunicación.
\end{abstract}

Palabras clave: proyección, imaginario, psicología, sociología, antropología.

\section{About the concept of projection and mapping in communicative world}

\begin{abstract}
This text focuses on the concept of imaginary projection, from its psicological and psicoanalitical inception, towards its philosophical, sociological, anthropological and communicative developments. It shows for the first time the richness and usefulness of its applications and it deepens into its complex articulation, which is really necessary to know more about communication.
\end{abstract}

Key words: projection,mapping, imaginary, psychology, sociology, anthropology

Referencia normalizada:

Aladro Vico, E. (2013) Sobre el concepto de proyección en el mundo comunicativo. Historia y Comunicación Social. Vol. 18 № Especial Octubre. Págs. 317-329

Sumario: 1.Introducción y primeras formalizaciones. 2. Raíces simbólicas del concepto. 3. La consolidación del concepto en Jung. 4. Proyecciones de alta y baja energía. 5 La tradición fenomenológica: noosferas, esferas públicas, universos simbólicos 6. El concepto de imaginario de Sartre y Morin. 7. Conclusiones. 8. Bibliografía.

\section{Introducción y primeras formalizaciones}

Este artículo analiza el concepto de proyección como categoría del mundo teórico aplicada a la comunicación. Este concepto tiene una larga historia, que deriva en aplicaciones en distintas áreas intrapersonales, interpersonales y sociales masivas de la comunicación humana. 
Aunque se trata de un concepto reconocido, su complejidad y riqueza merecen observarse con detalle. La psicología nos permite, mediante el concepto de proyección, abordar fenómenos comunicativos que están fuera del alcance de los enfoques sociológicos o antropológicos, vinculándolos con fenómenos fundamentales en la experiencia humana.

El concepto de proyección se origina en la psicología de comienzos del siglo XX, por influencia de los estudios sobre sugestión e hipnosis que tenían gran éxito en el siglo (Jung, 2008b: 40). Es Freud quien primero habla del complejo de proyección-identificación para concretar un tipo de transferencia psíquica, es decir, una operación de cambio de plano o traslado de representaciones, que se produce como consecuencia de algún tipo de trastorno emocional o afectivo (Freud, 1920 y 1972: 43 y ss).

Antes que Freud, otros psicólogos habían contemplado la psique humana como una estructura en las que las representaciones podían "tomar posesión del cerebro" (como en la obra finisecular de Charcot, citado por Jung, 2008b: 40), y en las que se podía producir una "fijación" de un afecto por efecto de dichas representaciones, como indicó antes que Freud, Breuer (ver siempre Jung 2008b: 40 (la obra de Breuer es de 1893)). La tarea de estos terapeutas pioneros consistía en desbloquear esos afectos fijados por las representaciones.

A partir de esa tesis, Freud concibe su estructura psicológica en diferentes cámaras o formas del yo (el ego, el id, el superyó) (cfr. Freud 2007), entre las cuales ocurren trasposiciones y dinamismos con las imágenes mentales, así como represiones y cierres ante las situaciones traumáticas. La proyección es citada por Freud como mecanismo de defensa, pues permite exteriorizar o trasponer un contenido inconsciente reprimido y dar expresión o fijar en una imagen un complejo. La proyección y la identificación son muy visibles en los fenómenos colectivos de adoración a un líder o de contagio masivo de emociones, y de hecho, Freud resaltó su importancia en la psicología colectiva, a partir de las indicaciones e influencia de Tarde y de Le Bon (Freud 1972 ).

Según Jung, la teoría psicológica de Freud, inspirada en los hallazgos anteriores de Charcot, Janet y Breuer, concibió la mente como un organismo dinámico en el que la proyección y la identificación son fundamentalmente fenómenos patológicos derivados de la acción de la información en las diferentes cámaras o áreas de la mente.

El mecanismo descrito por Freud, aunque el creador vienés no lo desarrollara por completo, tiene mucha importancia. (cfr. Freud 2007 vol. XV) Según el padre del psicoanálisis, todos los bloqueos que se producen entre las diferentes formas del ego tienden a ser compensados. Esta compensación, como si de un sistema hidráulico se tratara, equilibra la acción de un afecto o emoción reprimida mediante la aparición de su contenido en otra cámara de la mente.La mente humana proyecta e introyecta sus frustraciones o represiones de un modo no consciente, por ejemplo identificándolas o identificándose con determinado sujeto u objeto. 
Existen en la teoría psicoanalítica diversos tipos de proyecciones, como las sublimaciones, mediante las cuales el individuo proyecta todo su afecto hacia algo, en compensación a una carencia o represión inconsciente (este hallazgo debemos atribuirlo sobre todo a Alfred Adler), las personificaciones o identificaciones, en las que un afecto es proyectado mediante la identificación con alguien o algo por parte del paciente, invirtiendo el proceso en una introyección, la identificación proyectiva con la agresión temida, en la que los contenidos reprimidos pasan a ser sustituidos por sus contrarios, y las materializaciones de participación mística que estudió Lèvy Bruhl, en las que la asociación de un contenido psíquico con un objeto permite identificar intensamente ambos mediante una proyección. (ver en general Freud 2007, en particular los vols. III, VI y XIV).

Nos interesa señalar que la capacidad proyectiva es la capacidad para otorgar autonomía a los contenidos de la mente frente a la misma consciencia. Cuando una cognición se proyecta, adquiere vida propia en la mente del individuo. En el primer psicoanálisis esto se consideró enfermo, patológico. Pero Jung va a naturalizar esa capacidad y a estudiarla en su mayor profundidad, abriendo el paso a su estudio en el mundo interpersonal y social masivo de los medios de masas.

\section{Raíces simbólicas del concepto}

El concepto de proyección como hecho cognitivo se remonta siglos atrás en la cultura occidental. Si deseamos rastrear las raíces de la idea de la mente como entidad proyectiva tenemos forzosamente que ir hasta la Grecia platónica y presocrática, en la que las proyecciones físicas eran parte del culto mistérico de Eleusis. La primera forma de proyección física, la sombra, fue objeto de interés en la mente griega mitológica, y los misterios hacían uso del teatro de sombras además de proyectar visiones sagradas del mundo de las cosechas y de la naturaleza vegetal. También las sombras, proyecciones y efectos visuales serán objeto sagrado en el mundo asiático e hindú, dando lugar a diversas formas culturales, como el teatro de marionetas de Indonesia, revestido de valor espiritual, y las formas de danza y teatro asiáticas, en las que la proyección se convierte en una herramienta de la meditación.

En los misterios de Eleusis, se proyectaban sombras en las paredes de los recintos y cuevas, y la visión de este ritual inspiró ${ }^{1}$ a Platón, que practicaba esta religión griega, su legendario mito de la caverna (Platón, Libro VII de "La República", 1992). La mentalidad icónica occidental nace sin duda de esta raíz cultural, a la que debemos acercar todo el desarrollo iconológico de la cultura europea.

1 Ver entre otros Gracia, Josep, "El Mito de la Caverna" (http://www.arkho.com/grac9.htm,[consultado 15 agosto 2013] y su libro Simbólica Arquitectónica, Barcelona: Symbolos, 2004). El autor destaca el evidentísimo paralelismo entre los grados de sabiduría en el relato del mito de la caverna y los grados de iniciación en los Misterios eleusinos (miesis, telea y epóptiká. Es decir, purificación, conocimiento final y visión). 
En la teoría platónica la proyección es la base del funcionamiento de la mente humana. Nuestra experiencia, la forma de lo real, es proyectiva. Nuestra situación en el mundo se realiza mediante la proyección. Vivimos dentro de las proyecciones e ilusiones proyectadas, y salir de ellas o reconocerlas es la clave para alcanzar el conocimiento superior. Cuando el sabio consigue salir fuera de la caverna, como cuando el iluminado budista alcanza el conocimiento de su sí mismo, se libera de las proyecciones y no deja que le afecten emocionalmente.

No estamos lejos, a pesar de las distancias temporales, de la teoría gestáltica que reconoció igualmente la naturaleza proyectiva de la percepción en el concepto estructural de la Gestalt (Koffka, 1973). También en este caso el reconocimiento de las Gestalten o formas permite captar el relativismo de nuestra concepción de la realidad, y mostrar hasta qué punto cada fenómeno proyectivo determina la realidad en que vivimos.

Las cráteras presocráticas, las marionetas indonesias y otras formas de juego con sombras de las antiguas culturas son las primitivas formas de un gusto por la actividad proyectiva que podemos relacionar con la cinematografía, con las industrias y tecnologías de las formas icónicas, que tanto llamaron la atención a André Malraux.

El concepto de proyección platónica impregnará toda la filosofía cristiana primitiva, y así nos encontramos con la escolástica filosófica medieval donde las proyecciones siguen generando problemas fundamentales, por ejemplo en la filosofía tomista. Las formas y causas formales son también proyecciones, en este caso purificadas por el conocimiento profundo (cfr. Coomaraswamy, A. 1980). En la filosofía medieval existe consciencia respecto a la proyectividad de la mente, y se estudia en la escolástica de San Buenaventura o de Alain de Lille, de Santo Tomás o del Dante).

El iconismo de nuestra civilización se exacerba a partir del Renacimiento (vid. Malraux 1926). La mentalidad icónica absoluta del Renacimiento produce una cultura de la mímesis y la reproducción de imágenes, y genera las primeras formas de hipertrofia de la imaginación en sentido puro. Este fenómeno psicosocial queda patente con la llegada de los mecanismos de reproducción icónica técnica y el desarrollo de la imagen reproducida técnicamente, que de las formas teatrales, circenses, desarrolla después las cámaras oscuras, los autómatas, kinetoscopios, ilusiones ópticas, y por último la fotografía, el cine, la televisión y el video.

La proyección técnica, que desde los comienzos del fenómeno en la cultura clásica es resultado del gusto por los efectos imaginativos, y creó en Grecia el gusto por el teatro, la estatuaria y posteriormente por el icono religioso, tiene una dimensión más madura en las vanguardias artísticas, y en la imaginación creativa. Las técnicas proyectivas van desbocándose en los desarrollos tecnológicos cada vez más perfectos, y que llegan, hoy en día, a las herramientas digitales, la realidad virtual, las imágenes en 3D y el fabuloso mundo proyectivo navegable de la red. (David Jay Bolter es un buen estudioso de este proceso en Bolter 1999) 
Todo el desarrollo tecnológico de los medios de proyección debe explicarse como una carrera por favorecer la proyección imaginaria, es decir, la actividad imaginativa que, aunque en modo no consciente, se relaciona con las formas de los arquetipos esenciales : ántropos, zoóteos, axis mundi, imago mundi, mándala, anábasis, catábasis,enantiodrómos, ánima (Aladro 2010).

La tradición pragmática y la teórica, en torno al concepto de proyección, comienzan a fundirse con la llegada del cinematógrafo, que coincide con el surgimiento de las teorías sobre sugestión e hipnosis (Eugenio Cué, H. Poincaré, N. Hill) de finales del XIX y comienzos del XX. La confluencia entre el interés teórico y médico por las proyecciones mentales y la expansión tecnológica de la cinematografía nos conducirá a perfeccionar el conocimiento en torno a la proyección comunicativa, después de la guerra mediante la obra de Jean Paul Sarte primero (Sartre 1942), y de Morin después (Morin 1960).

\section{La consolidación del concepto en jung}

El gran beneficio que para la teoría comunicativa tiene la consolidación de este concepto de proyección viene del establecimiento del dinamismo que implica en el mundo de la comunicación intrapersonal. En la teoría de Freud es fundamental que el individuo sea consciente de sus proyecciones e identificaciones, es decir, traslade la consciencia hacia estos dinamismos psíquicos. Ello implica trasladar de nuevo las proyecciones al plano de la consciencia racional. La teoría freudiana desarrolla múltiples métodos como la terapia de charla, el flujo de memoria y la capacidad asociativa inconsciente, el análisis de los lapsus linguae o el test de Rorschach, para verlas y reconocerlas.

Como hemos dicho, las proyecciones son el fenómeno natural asociado a una estructura en contrapeso o hidráulica de la mente. En esa estructura lo que no circula es proyectado, imaginarizado, hacia otro ámbito de actividad. La homeostasis o el equilibrio de la mente hace que aquello que excede o bloquea la capacidad en una cámara de la mente pase a otra en forma proyectiva, mediante la imaginación y la fantasía. Un cambio de contexto mental supone un cambio afectivo en la psique humana, en la teoría freudiana. Del mismo modo, análogamente, que el significado de una palabra cambia según su contexto o su marco de referencia, el significado de un acto cambia si se proyecta a uno u otro plano de representación psicológica.

Si Freud es quien acuña y designa el concepto de proyección, Jung es el autor que lo naturaliza y amplía, especializándose en su dinámica y desarrollando la idea energética de la mente humana. Vamos a detenernos en las aportaciones de Jung porque aún no se ha destacado la importancia que tienen en el campo de la comunicación.

Jung amplia la raíz del concepto de proyección, comprobando que nuestra mente no enferma es proyectiva por naturaleza. Si Freud se centró en el mundo emocional y afectivo, Jung expande la idea de la actividad mental hasta considerar que las formas 
de nuestra psique son distintos tipos de actividades energéticas. Existe en Jung la idea de que el inconsciente y el consciente no son sino frecuencias de manifestación de la energía mental. La mente precisa que esta energía fluya y se desbloquee, pudiendo alcanzar las formas más profundas del inconsciente genérico humano, en las que desaparece el yo como tal y la mente se abre y conecta con una psique colectiva.

Jung acentúa la idea de que la energía reprimida o no fluyente en un plano psíquico, tiende a proyectarse hacia otro, de modo que, si por ejemplo, de la consciencia humana desaparece el reconocimiento de un plano sobrenatural o espiritual de la existencia, con sus formas de manifestación, esa energía bloqueada tiende a "constelarse", es decir, a proyectarse manifestada, en otro plano mental.

Los contenidos arquetípicos de la mente, expresión de efectos primigenios vivos en el alma (Jung 2007: 95) deben proyectarse de maneras deliberadas y respetadas por la consciencia en la expresión cultural y espiritual del grupo humano. Si no es así, si las visiones sintéticas y totales de los mitos no tienen representación en la consciencia, entonces el vacío que queda es suplido por proyecciones infantilizadas, patológicas o neuróticas. Muy interesante es el estudio que hace del símbolo de la svástica como proyección monstruosa de un contenido arquetípico religioso (la rueda solar y el axis mundi) al plano de la identidad nacionalista que a su vez es un sustitutivo sublimado del culto a la divinidad suprema desaparecido en la Alemania post-protestante (vid Jung 2009b: 144). ${ }^{2}$

Poco a poco el gran psicólogo suizo amplía la naturaleza de las actividades proyectivas y comienza a despatologizar el concepto. No solamente los enfermos psiquiátricos proyectan o introyectan: para Jung, toda la cultura es un sistema de proyecciones cuya función fundamental es dar un cauce digno a la conexión del individuo con la totalidad: "el mundo de representaciones...que no ha sufrido mutilaciones y tiene tras de sí una larga historia, ....al ofrecer al reino de figuras y creaciones inconscientes un digno recipiente en el que alojarse, confiere de este modo expresión visible a ciertas verdades de vital importancia con las que la consciencia debe estar en relación" (Jung 2008: 205).

Muchos arquetipos son espejo de los procesos que quieren producir: son proyecciones de la vida psicológica del individuo, que han traspasado la barrera intrapersonal para convertirse en parte de la herencia cultural de un pueblo. En todos los sentidos los arquetipos expresan un "numen" presente en ellos: provocan su contenido y lo expresan al mismo tiempo (Jung 1998: 262). Jung se dedicará a estudiar las proyecciones de todo tipo en las formas culturales, no desdeñando el estudio de

2 Jung, La vida simbólica, vol. II, 2009b: 141 (“Civilización en transición”): “podemos interpretar la svástica como una proyección de un intento colectivo inconsciente de formar una personalidad unificada compensadora. Este intento inconsciente desempeña una función muy importante en la personificación general del Estado. Le da su cualidad de fantasma y la posibilidad de encarnarse en una personalidad humana. En cierto sentido, la autoridad casi personal y la aparente eficacia del Estado no son nada más que la constelación inconsciente de una personalidad instintiva superior que compensa la palmaria ineficacia de la personalidad yoica consciente". 
todas las formas representativas, del período o área que sea, que son proyecciones de arquetipos.

\section{Proyecciones de alta y baja energía}

Jung (2009b: 134 y ss.) distingue entre proyecciones de baja energía y de alta energía. Es importante su diferenciación porque en el proceso de cambio de plano, una proyección puede perder energía psíquica, o ganarla. Si pierde energía y se convierte en una copia mediocre de su origen, será una forma de baja energía. Si en el proceso el arquetipo recupera fuerza y se liga más fuertemente con su energía de origen, es una forma de alta energía.

La idea parte de la concepción de onda energética para la actividad mental. Un cambio en la superficie o plano en que la energía se emite cambia su longitud de onda, como cambiaría por ejemplo la trayectoria de un objeto si viaja en el aire o atraviesa el agua. El cambio de longitud de onda hace que lo proyectado transforme su energía, la intensifique o la aminore. Exactamente esto es lo que ocurre en los planos o cámaras de la mente humana, y la diferencia de carga energética marca que las representaciones estén en la consciencia o en la inconsciencia (ver Jung 2009b: 184).

Entiende Jung que existe actividad proyectiva en la creación de la imaginación fantástica y de la ficción, que forzosamente se ponen en conexión con el fondo de los arquetipos. Pero la imaginación, la ficción, suponen formas proyectivas de baja energía, en las que existe un distanciamiento personal frente a la proyección. Estas proyecciones, son formas energéticamente bajas puesto que pierden la conexión con la fuerza del inconsciente profundo que proporciona explicaciones no racionales de la estructura universal. Estas formas proyectivas surgen como compensación al proceso de racionalización que sufre la cultura occidental en los últimos cinco siglos, en el que la parte irracional de la mente es barrida fuera de la atención y respeto consciente de la mente humana. En un movimiento de equilibrio, el inconsciente proyecta formas secundarias de su contenido, que suponen el hiperdesarrollo de la imaginación y la ficción, en la cultura occidental.

Las formas superficiales o vaciadas de cultos religiosos, el uso estético de la simbología, el juego con los estilos artísticos, el uso de mitos o arquetipos implícitos en publicidad, el culto a la imagen del yo, en la fotografía personal, en las redes sociales, son según esta teoría formas proyectivas de baja energía. En ellas los arquetipos son "sombras", difícilmente accesibles, y el proceso que ha tenido lugar es de decrecimiento o de pérdida de energía psíquica. El inconsciente es más oscuro e insondable que nunca, y las formas simbólicas se generan de un modo no reconocido, como formas "estéticas", imaginativas o fantasiosas, sin ningún valor o utilidad primarios más allá del mero gusto o capricho. Se las trata como excrecencias de la sociedad de consumo y del sistema masificado de vida urbana. Su función es meramente compensatoria frente a la consciencia global centrada en la propia mente lógica y racional. 
Las proyecciones de alta energía son aquellas en las que la fuerza psíquica asociada es intensa y nos lleva o traslada al ámbito de la relación del hombre con el universo, con las formas de existencia, en forma consciente y deliberada. Son aquellas en las que se produce un traspaso de experiencia intenso, una visión deliberada. La creación artística, la forma más alta de energía proyectiva, saca a la luz arquetipos que permanecían ocultos en formas proyectivas de baja energía, para recargarlos de riqueza simbólica, de significados asociados en múltiples planos. Se trata de auténticos medios de comunicación entre el hombre y la vida que realmente le rodea.

Estas son las formas más complejas de la actividad proyectiva, pero son tan importantes que explican el completo fenómeno de la cultura y la actividad espiritual humana. Cuando una civilización debilita en extremo la alimentación de sus proyecciones arquetípicas, puede experimentar proyecciones patológicas, regresiones al mundo instintivo, retornos a formas brutales de experiencia. La energía, afirma Jung, precisa de los opuestos para alcanzar equilibrios, tal y como la simbología universal nos presenta visualmente (enantiodrómos como el yin y el yang, la balanza egipcia, el ourobóros o las frases de Heráclito son formas de equilibrio de opuestos). Solamente es posible alcanzar planos superiores de desarrollo cuando se equilibra la carga mediante el juego de opuestos. La cultura y el arte, o la espiritualidad, son el "opuesto" al inconsciente y el "opuesto" a la racionalidad al mismo tiempo, es decir, son el plano superior: en sus proyecciones de alta energía.

\section{La tradición fenomenológica: noosferas, esferas públicas, universos simbólicos}

En el mismo momento en que Carl Jung realiza estas reflexiones sobre el concepto de proyección, las mismas ideas han resurgido en ramas de la filosofía, el pensamiento social y en ciencias nuevas que estudiarán la dimensión social del concepto de la proyección. En el pensamiento religioso, formas filosóficas han tratado las primeras esos mundos denominados "ciudades de dios" (San Agustín), "noosferas" (Teillhard de Chardin) o "casas del ser" (Werner Heidegger) asociadas a los símbolos, representaciones mentales, y al lenguaje. En contacto entre ellas, las disciplinas nuevas que surgen en el siglo XX, como la fenomenología filosófica, la filosofía del lenguaje, la semiótica, la fenomenología social, van derivando el análisis de los fenómenos proyectivos a distintas áreas de la vida colectiva.

Podemos considerar que el concepto de "esfera pública" que enuncia el filósofo alemán Jürgen Habermas $(1962,1981)$, es heredero de la tradición proyectiva. Igualmente la fenomenología social de Alfred Schutz, con Thomas Berger y Peter Luckman (1991), acuña el concepto de "universo de significado o universo simbólico", utilizando conceptos psicoanalíticos (internalización, externalización, objetivación). Las concepciones semánticas del lenguaje de Saussure o Peirce, herederas de la lingüística escolástica medieval, van adoptando progresivamente y de manera creciente la analogía proyectiva: de los "significados", se pasa a hablar de campos semánticos, 
isotopías y espacios de sentido. La fenomenología social funde a finales del siglo XX el estudio de las realidades macrosociales -las civilizaciones, las ciudades, las culturas-, con el aparato conceptual proyectivo proveniente de la tradición psicológica.

Al rescatar instrumentos teóricos como el concepto de participación mística, la magia asociativa, la criptestesia pragmática, la antropología nos devuelve al espacio mágico de la experiencia primitiva y naturaliza estos fenómenos en la óptica académica. La antropología se desgaja de la filosofía simbólica, conservando relación con la filosofía de las religiones, con la sinología y con la filosofía de la historia. De su vocabulario teórico emergerán en el siglo XX conceptos que trasladan el interés por fenómenos proyectivos al ámbito de la comunicación, como por ejemplo los de representación, comunidades imaginadas y espacio sagrado o espacio simbólico. (ver por ejemplo las obras de Appadurai, Castoriadis, Thompson, o B. Anderson entre otros).

\section{El concepto de imaginario de sartre y morin}

Las obras de Jung y Freud se convierten a comienzos del siglo XX en una teoría muy popular. Jean Paul Sartre será uno de los primeros autores de la filosofía en reflexionar sobre esos procesos proyectivos aplicados a la vida social contemporánea. En su obra L'imaginaire, de 1940, y en su ensayo anterior L'imagination, de 1936, Sartre polemiza con la teoría de Jung al afirmar que lo imaginario representa el sentido implícito de todo lo real, y es una especie de percepción renovada.

El impacto de las ideas psicológicas está formando, en esos momentos, parte del corpus de investigación sobre los nacientes medios de comunicación de masas. En 1951 Kurt y Gladys Engel Lang, matrimonio de investigadores afincados en la Escuela de Chicago, tienen acceso a la obra de Sartre y en uno de sus artículos de investigación mencionan la necesidad de estudiar el impacto que la "imaginería" de los medios produce en los públicos. (Lang, G., y Lang, K. 1985).

El concepto de imaginario de Sartre, tomado directamente de las ideas jungianas y de la discusión fenomenológica y filosófica de la historia europea, será transformado en la imaginería mediática por los Lang, para volver a caer en manos de otro investigador europeo que amplía enormemente el valor de la idea: es Edgar Morin, quien a comienzos de los años 60 del pasado siglo publica dos textos fundamentales: Le cinéma ou l'homme imaginaire (1956), y L'esprit du temps (1962).

Morin, apoyándose en las ideas de Sartre y Malraux aborda los fenómenos proyectivos de la comunicación de masas. Inicialmente su estudio es sobre las formas proyectivas en el cine. Acuña el concepto de imaginario colectivo, similar a los de esfera psíquica o noosfera, pero con una ambición más generalista y sirviéndose de la analogía con la psique individual jungiana: el imaginario es el conjunto de representaciones, de proyecciones, de formas que existen en una cultura en un momento dado. Provienen esas formas de los arquetipos, y esta proyección global, creada por los modernos medios de comunicación, rescata formas arcaicas de cognición simbólica 
produciendo por primera vez en la historia una globalización comunicativa en torno a las dinámicas de arquetipos reconvertidos en formas de la cultura de masas (1962).

Pero Morin no solamente continúa la línea de trabajo de los psicólogos sociales, antropólogos o expertos de fenomenología social. Su teoría es muy innovadora. Introduce la idea de la correspondencia y retroalimentación entre vida imaginaria y vida material. Las proyecciones al imaginario son enriquecidas por las identificaciones materiales y prácticas que produce la sociedad de consumo. Cada forma del imaginario va asociada a un aspecto práctico o material de la cultura, y con ello, adquiere energía en la psique colectiva. Es una trasposición de las dinámicas proyectivas estudiadas en el psicoanálisis de lo más original y creativa.

El sistema técnico de la cinematografía ha inspirado la idea proyectiva al excineasta Morin. Tras él, tanto Castoriadis (griego) como Appadurai (hindú) han comprendido la oposición existente entre proyecciones creativas e imaginativas y proyecciones al servicio del sistema consumista y las relaciones pragmáticas de la vida social. Es llamativo que este último autor no reconozca la filiación del concepto que él estudia en los autores que venimos recordando aquí.

Probablemente con Marshal McLuhan, el francés sea el inaugurador de una saga de investigadores que enriquecen sus reflexiones aplicando las analogías mediológicas al sistema social general. Ambos constituyen, con Raymond Williams y la escuela de Birmingham, los investigadores a los que debemos una gran influencia a la hora de estudiar las relaciones estrechas entre proyección cultural y proyección psicológica.

Williams ha sido clave al recordar que los sistemas de los medios de masas se alejan de las formas simbólicas y tienen escasa conexión con las proyecciones culturales de alta energía. McLuhan indicó cómo el crecimiento hipertrofiado de las extensiones y mediaciones tecnológicas proyectivas produce un efecto de narcosis en el que partes de la sensibilidad y la consciencia se pierden por efecto de la ley de atrofia de la mediación (Mc Luhan y Mc Luhan, 2009). De Mc Luhan llega la idea de la proyección sensorial que producen los medios tecnológicos (McLuhan 1964, 2002). Las personas extendemos nuestro campo sensorial al extremo de las herramientas que utilizamos, llevando a cabo un proceso que posteriormente ha sido llamado mente extendida (Chalmers, D. y Clark, A., 1998)

La modernidad trae, casi por coincidencia absoluta, el desarrollo de sistemas técnicos de proyección cada vez más perfectos, en los que la creación de la ilusión de realidad está muy lograda. Ello acelera enormemente la actividad psicológica imaginativa en el mundo global de finales del siglo XX y comienzos del XXI.

Son muchos los autores atentos a estos procesos, que analizan la interacción entre la psique y las máquinas del última generación. Estos investigadores (Johnson, Thompson, Manovich, De Kerchove son solamente algunos nombres) han notado que la revolución digital no sería tan enorme y acelerada si no existiera un cultivo previo de la facultad imaginativa que desde el mundo antiguo ha venido hiperdesarrollando las formas proyectivas, la imaginación, la fantasía llevada sobre diversos soportes. 
El análisis de las interfaces culturales, las formas en las que por fenómenos proyectivos se extiende la capacidad tecnológica de un medio, y los sincretismos y re-mediaciones que esas proyecciones permiten son uno de los campos más brillantes de la última investigación sobre nuevos medios y digitalidad (Manovich, Lev, 2006, Bolter, David, 1999).

\section{Conclusiones}

El camino hacia el análisis de la proyección como fenómeno general de la comunicación humana no ha terminado de ensancharse todavía. La proyección como operación natural de la mente en colectivos, es el origen del análisis del imaginario, los universos simbólicos y los espacios de significado que la sociología, la antropología y los estudios de opinión pública abordan crecientemente.

El constructivismo en su versión sociológica y en su vertiente antropológica, que son tendencias de investigación de gran crecimiento, se ven enriquecidas si las ligamos con el concepto de proyección que Jung desarrolló desde su visión energética de la psique.

Las proyecciones cumplen en diversos ámbitos una función comunicativa compleja. Es necesario que tengan alta energía. Del mismo modo que existe un uso deliberado e intensísimo de las dinámicas proyectivas en el sistema de la cultura de masas, para alimentar el sistema de consumo, debería también existir una conciencia deliberada, es decir altamente energética, de la necesidad y función más vital de la capacidad proyectiva: dar expresión a las sagradas formas de la existencia. Muchas de las proyecciones que actualmente alimentan y saturan la comunicación a todos los niveles no pueden conectarnos con los arquetipos. Se trata de la fotocopia de la fotocopia de la copia de aquello que les dio origen, y prácticamente en ellas no puede leerse nada.

Cuando una proyección no se hace consciente acaece externamente como destino (Jung 1992: 81). Somos cuanto imaginamos, dibujamos, proyectamos. La exacerbación de la imaginación, de sus formas, está marcando claramente la falta de control, la falta de respeto y de conciencia respetuosa, hacia la energía psíquica. El dolor humano es otra señal de que hay cosas que no están en su sitio, que no han recibido el puesto que deben de tener en la mente humana y en la cultura universal.

\section{Bibliografía}

ALADRO, E. (2010). "La estructura de los símbolos" en Perspectivas de la Comunicación, vol. 3, $\mathrm{N}^{\mathrm{o}} 2$, pp 134-147.

APPADURAI, A. (1996). Modernity at Large. Minnesota: U. of Minnesotta Press. 
BERGER T y P. (1991). La construcción social de la realidad. Buenos Aires: Amorrortu.

BOLTER, D.J. (1999). Remediation. Cambridge: Cambridge University Press.

CASTORIADIS, C. (2007). La institución imaginaria de la sociedad. Barcelona: Tusquets.

CHALMERS, D. y CLARK, A. (1998). "The extended mind", Analysis 58, pp-1023.

COOMARASWAMY, A.,(1980). La filosofía cristiana y oriental del arte. Madrid: Taurus.

ELIADE, M.(2010). La isla de Eutanasius. Madrid: Trotta.

JUNG, C. G. (1998). Simbología del Espíritu. México: Fondo de Cultura Económica. (2001) Contribuciones a los simbolismos del sí mismo. Barcelona: Paidós.

(2007). Sobre el fenómeno del espiritu en el arte y en la ciencia. Madrid: Trotta. (2008a) Acerca de la psicología de la religión occidental y la religión oriental. Madrid, Trotta.

(2008b) La Vida Simbólica. vol 1. Madrid: Trotta.

(2009a) Arquetipos e inconsciente colectivo. Barcelona: Paidós.

(2009b) La Vida Simbólica vol. 2. Madrid: Trotta.

FREUD, S. (1972, 1920). Psicología de las masas y análisis del yo. Madrid: Alianza Editorial. (2007). Obras Completas. Madrid: Amorrortu.

GRACIA, J. (2004). Simbólica arquitectónica. Barcelona: Symbolos.

HABERMAS , J.( 1981, 1962). Historia y Crítica de la Opinión Pública. Barcelona: Gustavo Gili.

HEIDEGGER, W. (1955). El ser y la nada. México: Fondo de Cultura Económica, HUSSERL, E. (1944) Ideas relativas a una Fenomenología pura. México: FCE.

JENKINS, H. (2005) Convergence Culture. Barcelona: Paidós.

DE KERCKHOVE, D. (1999). Inteligencias en conexión. Barcelona: Gedisa.

KOFFKA, K. (1973). Principios de Psicología de la forma. Barcelona: Paidós.

LANG, K., y LANG, G. (1985). "Los mass media y las elecciones" en Moragas, M. (1985). Sociología de la comunicación de Masas. Barcelona: Gustavo Gili.

LÈVY BRUHL, L.(1985) El alma primitiva. Barcelona: Península.

MALRAUX, A. (1926). La Tentation de l'Occident. Paris: Grasset. (1992). Las Voces del Silencio, Obras Completas, Paris: La Pleiade,

MANOVICH, L. (2006). El lenguaje de los nuevos medios de comunicación, Barcelona: Paidós.

MCLUHAN E. y MCLUHAN M. (2009). "Las leyes de los medios", en Cuadernos de Información y Comunicación CIC, número 10, Universidad Complutense de Madrid, pp. 285-316.

MCLUHAN, M. $(2002,1964)$. La comprensión de los medios como extensiones del hombre. Barcelona: Paidós.

MORIN, E. (1956). Le cinéma ou l'homme imaginaire. Paris: Minuit . (1962). L'esprit du temps. Paris: Grasset.

PLATÓN (1992). "Libro VII de "La República"”, en Diálogos. Madrid: Aguilar. 
SARTRE J. P. (1936). L'imagination. Paris Gallimard (1942) . L'Imaginaire. Paris: Gallimard .

TEILHARD de CHARDIN (1988). El puesto del hombre en el cosmos. Barcelona: Planeta.

WILLIAMS R. (1974). Los medios de comunicación. Barcelona: Península.

\section{La autora}

Eva Aladro Vico, nacida en Madrid en 1963. Doctora en Periodismo en 1991. Profesora Titular de Teoría de la Información en la Universidad Complutense de Madrid desde 1996. Ha ejercido la docencia en Madrid, en la Facultad de Ciencias de la Información, desde 1992 y esporádicamente en Salamanca (Universidad Pontificia) y la Universidad de Las Palmas de Gran Canaria. Ha publicado diversos artículos y libros sobre temáticas de las materias Información, Comunicación, Periodismo Profesional, Medios de Masas, Ética Informativa, estado actual de las investigaciones en estos campos, epistemología y crítica de la materia en revistas profesionales del sector, como Cuadernos de Información y Comunicación ( Universidad Complutense de Madrid) revista académica de la que es actualmente Directora.

Por su conocimiento de lenguas ha elaborado traducciones de textos originales de autores prestigiosos en el campo de las Teorías de la Comunicación e Información, que han sido publicadas por la revista CIC de la Universidad Complutense, de la que es actualmente la coordinadora. También ha ejercido la traducción literaria.

Ha publicado tres libros "Teoría de la Información y la comunicación efectiva" (Madrid, Fragua, 1998) y "Comunicación y retroalimentación" (Madrid, Fragua, 2004), "La Información determinante" (Madrid, Tecnos, 2009) Así como numerosos artículos y colaboraciones en el ámbito de la universidad, con algunas colaboraciones en publicación internacional.

Actualmente es Directora del Departamento de Periodismo III, Facultad de Ciencias de la Información, Universidad Complutense de Madrid. 